\title{
CULPA Y EXPIACIÓN
}

\author{
DANIEL DREWSKI \\ Universidad Humboldt de Berlín
}

\begin{abstract}
RESUMEN: En el siguiente ensayo se bosqueja la relación entre un concepto de lo político como contienda agonal y la comprensión particular del crimen y el castigo que se siguen de aquel. Partiendo de una interpretación freudiana de la evolución cultural (cuya fuente sería el impulso erótico y el agresivo), se examina el rol de lo político como campo de juego en que se enfrentan ambos impulsos, constituyendo identidades políticas entre lo universal y lo particular. Agregando a esta lucha agonal el castigo como tercera coordenada, se lograría un entendimiento sustancial de las prácticas punitivas, que se alimentan directamente de la comprensión de culpa que rige en las comunidades políticas como entidades que se forman agonalmente.
\end{abstract}

Palabras clave: Crimen, castigo, culpa, concepto agonal de lo político, agresión.

ABSTRACT: In the following essay there is an outline of the relation between a concept of the political as an agonistic dispute and the particular understanding of crime and punishment which would thereof follow. Starting from a Freudian interpretation of cultural evolution (its source being the erotic and aggressive drive), the role of the political as a field where both drives collide is examined, constituting political identities between that which is universal and that which is particular. Adding punishment to this agonistic contest as a third coordinate, punitive practices could be conceived in a substantial manner, gaining significance directly from the comprehension of guilt which prevails in political communities as entities formed in agonistic struggle.

Key words: crime, punishment, agonistic concept of the politica, aggression.

El título original de la obra de Fiódor Dostoyevski "Prestuplenie i nakazanie" parece no tener un equivalente exacto en el idioma alemán, pues se han visto diferentes traducciones del mismo: desde el tradicional "Culpa y Expiación" hasta la más moderna versión de Swetlana Geier "Crimen y Castigo" 1 . La diferencia es evidente: el primer título con contenido altamente moralizante se opone al segundo más técnico, que tiene la forma de un simple silogismo jurídico. No soy capaz de esgrimir los argumentos idiomáticos que apoyan una u otra traducción, pero pretendo dar una interpretación de sus diferencias semánticas en el marco de un concepto de lo político dinámico o agonal que desarrollaré más adelante. Creo que dentro de este será posible diferenciar de un modo fructífero entre ambos significados -lo cual, por supuesto, pretende ser una interpretación no solo con pertinencia respecto de la obra determinada, sino un análisis general de la relación entre la política y el castigo-. Estimo que hay una profunda diferencia filosófica en afirmar que una persona determinada se ha hecho culpable de un delito o si meramente ha cometido un crimen. Análogamente, si a causa de este debe expiar o ser castigado. La diferencia no solo se haría evidente en el plano psicológico -dependiendo de la definición situacional subjetiva que propone para sí el individuo- sino que se relaciona directamente con el

\footnotetext{
*Estudiante (segundo semestre) de Sociología, Ciencias Políticas y Filosofía.

${ }^{1}$ Confusión que no se presenta en las traducciones castellanas.
} 
modo de comprender la comunidad o las identidades políticas. Pretendo mostrar entonces que una comprensión del problema solo se adquiere analizando el concepto de lo político.

\section{UN CONCEPTO AGONAL DE LO POLÍTICO}

"Amad a vuestros enemigos, bendecid a los que os maldicen, haced bien a los que os aborrecen, y orad por los que os ultrajan y os persiguen”. (Mateo 5:44): la exigencia última, imposible del superego cultural, destinado a la supresión de aquel impulso destructor tan humano, y a la vez origen del "malestar en la cultura" 2 , del sentimiento de culpa que nos persigue con la interiorización del pecado original.

"Amad a vuestros enemigos": el mandamiento de un superego antipsicológico, fuente de reproducción necesaria del sentimiento de culpa, al ser la agresión el impulso más natural de la especie humana, que aún suprimido despliega sus efectos nocivos quedando siempre al descubierto ante el tribunal rigoroso del superego-panóptico.

"Amad a vuestros enemigos" significa amar a los más desiguales, a los antípodas de la propia existencia, significa omitir diferencias y situarse en el plano abstracto de la total igualdad de la naturaleza humana: significa amar todo y nada, pues nada sustancial queda por ser amado, por constituir el objeto del eros cultural.

Estas son, según Freud, las dos fuentes la evolución cultural: el eros y la muerte, el aglutinamiento libidinoso y el pulso destructor, el amor que debe trascender el objeto preciso y dirigirse a la totalidad: un amor trabado, pues, y una agresión precisa que se suelta contra lo extraño.

En cierto sentido una concepción demonológica de la evolución cultural, evocando un espectro que divaga entre el aquí y el más allá: la agresión que no permite trascender de lo particular a lo absoluto. En esta tiniebla precisamente residiría lo político. En consecuencia, una especie de encanto morboso emana de aquellos teóricos políticos maquiavelistas, hobbesianos, sobre todo schmittianos (precisamente la tradición "demonológica" del pensamiento político, como diría Dolf Sternberger ${ }^{3}$ ) que aparentemente se funda en esta interpretación tenebrosa de la conditio humana -encarcelado en un purgatorio entre lo terrenal y celestial- y se dirige contra cualquier intento aristotélico de fundar el concepto de "lo político" sobre la base de un criterio de lo bueno, en miras de lo justo, el justo medio (a menudo nos desean la ingrata "bienvenida a la realidad").

Lo político en interpretación demonológica es aquel campo de la práctica humana que se preocupa de marcar fronteras, de diferenciar entre un "nosotros" y un "ellos", entre amigos: objetos del eros, y enemigos: blancos de la agresión, en el que se logra, para bien o para mal, la transformación del impulso destructor humano en una categoría constitutiva de la comunidad política. Lo político no daría cabida a algún argumento ético, económico, estético, etc., pues este sería virtualmente violado por un antagonismo que exige su planteamiento en términos meramente políticos: ¿Estarías dispuesto a exterminar a tu adversario?

2 Freud, Sigmund. Das Unbehagen in der Kultur. -10a edición- Alemania: Frankfurt am Main, Alemania: Fischer Taschenbuch Verlag, 2007.

${ }^{3}$ Sternberger, Dolf. Drei Wurzeln der Politik. -1era edición- Alemania: Frankfurt am Main, Suhrkamp, 1984. 
En este sentido, lo político es una categoría absoluta: no hay ninguna disputa que no pueda convertirse súbitamente en una cuestión política y una vez así entendida, exige una toma de posición que niega existencialmente a aquella antagónica, la que no fue tomada. A la vez, lo político no es necesario, pues es perfectamente posible imaginarse un mundo sin antagonismos políticos. Así, los teóricos demonológicos se convierten en profetas de maravillosas escatologías. Lo demonológico y lo escatológico son engendros de la idea misma de la política como un campo de batalla existencial. La imagen divina guía al alma, seducido por lo político y por eso preso en el purgatorio.

Una interpretación particularmente lúcida del poder constituyente como esencialmente político, que permite esclarecer la idea de la exclusión como intrínseca a cualquier interpretación en tradición "demonológica" ${ }^{4}$, nos da Fernando Atria al plantear que la voluntad absoluta al constituirse "debe negar las potencialidades no actualizadas". En vez de crear una comunidad política, el poder constituyente se retira para dar lugar a lo constituido: "remueve [...] las posibilidades sobrantes" 5 . En cierto sentido, se purga lo heterogéneo para dar lugar a lo homogéneo. Sin embargo, se deja abierta la pregunta acerca de las cualidades que constituyen el criterio significativo de homogeneidad: se deja abierta como condescendiéndole al hombre una pequeña ilusión de libertad después del ocaso de los dioses.

Lo cierto es que la igualdad sustancial que exige $S c h m i t t^{6}$ como categoría constitutiva de la comunidad política, en oposición a aquella igualdad abstracta, lívida que pregona el liberalismo se diferencia solo gradualmente de esta última, pues ambas constituyen solamente el término de una escala que paso a paso aumenta (o disminuye) la exigencia de homogeneidad, hasta llegar a aquel punto en el cual, en sentido más abstracto, somos todos iguales en tanto ser humano (o todos diferentes -iguales solo consigo mismo- en tanto individuos). Supongo esta formulación del problema como conocida gracias a la divulgación que ha experimentado el programa pluralista en la órbita académica de la Facultad de Derecho por el profesor M.E. Orellana ${ }^{7}$. Claro está que al llegar aquel punto en el cual todo ser humano puede ser considerado como igual en razón de su pertenencia a la raza humana, lo político se disolvería, pues no habría lucha por aquel criterio sobre lo que debe entenderse como "igual". La definición de las "cualidades de homogeneidad significantes", por ende, no se da naturalmente, no es algo a constatar empíricamente (o a revelar mediante la acclamatio), sino es la puesta en escena de un criterio sobre aquello que es digno de ser amado por en algún sentido asemejarse a uno, un criterio que separa o excluye aquellas identidades que no son iguales por no poder ser objetos del eros (es menester "darle a cada uno lo suyo": lo igual para los que son iguales, lo desigual para los desiguales; amar a los que me aman, odiar a los que me odian). La lucha que se despliega desde aquel criterio de igualdad es la lucha política: ¿Quiénes son iguales, quiénes no lo son? ¿Quiénes merecen ser amados y quiénes objetos de agresión?

\footnotetext{
${ }^{4}$ Sigo utilizando este término solamente en calidad heurística.

${ }^{5}$ ATRIA, Fernando. "Sobre la soberanía y lo político", en Revista Derecho y Humanidades, Facultad de Derecho, Universiad de Chile, $\mathrm{N}^{\circ} 12,2006$, p. 71.

${ }^{6}$ SchmitT, Carl. Die geistesgeschichtliche Lage des heutigen Parlamentarismus. -6ta edición- Berlín, Alemania: Duncker und Humblot, 1985.

7 Orellana, Miguel E. Pluralismo: una ética del siglo XX. -2da edición- Santiago, Chile: Editorial Universidad de Santiago, 1996.
} 
Algo equivalente podría decirse de aquel punto en el que somos todos diferentes: Lo político no sería posible, pues el criterio de igualdad/desigualdad está ya trivialmente dado por ser uno igual a uno mismo. La vida en guerra permanente sería "solitaria, pobre, desagradable, bruta y breve" (emblemática frase de Hobbes). La imagen a la cual quiero llegar es la siguiente: La "igualdad sustancial” de Schmitt (o, digamos, la "identidad" ¿idéntico a quién, con quién?), es un momento contingente entre los dos polos de total igualdad o total diferencia. Definir identidades entre lo más concreto y lo más abstracto, sin llegar nunca a alguno de esos polos, es el objeto de la lucha política. La política es, pues, un purgatorio permanente, la lucha entre el eros que exige lo más abstracto, y el impulso destructor, que anhela la total fragmentación. Lucha agonal, más que confrontación antagonística, es lo político ${ }^{8}$.

Agon: Juegos públicos griegos en honor a los dioses, enfrentamiento individual en servicio al bien público: eros y combate. La agónica carrera de Aquiles contra la tortuga adelantada, acortando la distancia entre los dos siempre por la mitad: imposibilitado el acercamiento, la igualdad en la meta. Así está trazado el campo de juego, entre lo que hace en algunos sentidos iguales a Aquiles y la tortuga, por juntos participar en una contienda agonal, y lo que en otro sentido los permite comprender como totalmente distintos. Comprendo la agonía como esta tensión entre lo abstracto y lo fragmentario, la pugna vital entre ambos polos.

\section{UN CONCEPTO LETÁRGICO DEL CASTIGO}

Castigo: Exclusión del juego, término de la agonía, letargia, interrupción del combate y suspensión de lo político. En razón del reconocimiento de la igualdad del otro se toma la decisión de castigarlo, de sacarlo fuera de juego. El castigo es la negación de lo político al nivel de la misma identidad. Reconoce la igualdad del otro ya no en términos abstractos, sino en relación a términos concretos que constituyen una identidad. El delincuente comparte una misma identidad y se encuentra así a la vez en el seno de la sociedad y en lo limítrofe con lo extraño.

El panóptico de Bentham se convierte en paradigma de una sociedad disciplinaria, parcelando, clasificando, ordenando, jerarquizando lo inordenable, el caos inmundo, la masa promiscua, ejecutando control sobre los movimientos infinitesimales del cuerpo humano y ejerciendo una microfísica de poder en los intersticios y vericuetos del cuerpo social, bajo un estricto criterio de homogeneidad universal, en fin, incorporación del sujeto al mecanismo de producción y a la economía del poder en la cual cada partícula se mueve como pieza de un todo orgánico. Existiría un "continuo de calabozo" desde los mecanismos de penalización, pasando por el régimen penitenciario hasta la sociedad disciplinaria ${ }^{9}$. Desde el límite de la sociedad: del crimen, de los asilos, de los cuarteles surge un modelo de ejecución del

\footnotetext{
${ }^{8}$ Mouffe, Chantal. Über das Politische. Wider die kosmopolitische Illusion. -1era edición- Alemania: Frankfurt am Main, Suhrkamp, 2007. Quiero recalcar sin embargo, que comprendo aquí, en oposición a Mouffe, la agonía de lo político como aquel vaivén entre los dos impulsos identificados anteriormente.

${ }^{9}$ FouCAult, Michel. Überwachen und Strafen. Die Geburt des Gefängnisses. -1era edición- Alemania: Frankfurt am Main, Alemania, Suhrkamp, 1994.
} 
poder que se extiende por sobre toda la sociedad, y, sobre todo, que se integra a las operaciones políticas de la comunidad de citoyens. El conocimiento específico que surge de aquellas lagunas en principio insondables hace posible la constitución de la delincuencia controlada, de una sociedad aparte en el seno de la comunidad hegemónica, que neutraliza el potencial (político) conflictivo de las clases dominadas. Permite controlar la ilegalidad mediante la creación de la delincuencia como sujeto de dominación y objeto del saber.

La imagen más potente de la sociedad disciplinaria, del panóptico total:

"Moralistas, filósofos, legisladores, lisonjeros de la civilización: aquí está el plan de vuestro París ordenado, el plan completo, en el cual todas las cosas corresponden. En el centro y dentro del cerco interior: hospitales de todas la enfermedades, asilos de todas las miserias, manicomios, cárceles, presidios para hombres, mujeres y niños. Alrededor de la primera cerca cuarteles, cortes, administración policial, cuartel de pacos, patíbulos, vivienda del verdugo y sus asistentes..."10

He aquí, pues, la comunidad que logra exaltar al eros y a la vez neutralizar el impulso de fragmentación en una sociedad panóptica-disciplinaria. En la sociedad total, apolítica, la agonía se reemplaza por la disciplina letárgica y, podríamos decir, por el amor incondicional al símbolo fálico representado en la torre central de la construcción panóptica. El sentimiento de culpa colectivo es el resultado necesario de la constitución del castigo como instrumento del poder y operación política que se disuelve a sí misma. Sociedad total Estado omnipresente.

Las prácticas penitenciarias medievales descritas por Foucault cumplen precisamente la función contraria: la destrucción total del cuerpo del condenado en un espectáculo terrible de despliegue total del poder soberano. Sin embargo, el ritual deslumbrante deja en evidencia la posibilidad de un mundo oscuro, indomable, popular, que se sustrae al ejercicio soberano del poder, y por lo mismo es posible lugar de una probable amenaza. Las fiestas espontáneas que se forman alrededor del pobre martirizado a menudo se levantan contra el soberano mismo al identificarse con el destino del condenado. Evidente es el desenfreno del corpus social fragmentado y la neurosis colectiva que se excita ante el espectáculo de la violencia última: la liquidación total del cuerpo humano. El eros no lograba constituir la humanidad abstracta como "ese oscuro objeto del deseo" y se contentaba con el espectáculo sádico de la tortura. Y lo que es lo mismo: El castigo como destrucción lograba evacuar el impulso agresivo del ser humano, mientras que el castigo funciona hoy precisamente como supresión de este mismo, en el marco de la sociedad disciplinaria:

"los hijos lo odiaban [al padre], pero también lo amaban; después de que el odio se había satisfecho con la agresión, traslucía, a través del arrepentimiento, el amor, erigía, identificándose con el padre, el superego, le daba el poder del padre, como para castigar aquel acto de agresión contra él y creó las limitaciones que evitarían la reiteración del acto" 11 .

${ }^{10}$ Ibid., p. 396. La traducción es mía.

${ }^{11}$ FREUD, Sigmund. op. cit. (n. 2), p. 95. 
Ejemplarmente, la forma más inocua de soltar la agresión es mediante el chiste prejuicioso con tendencia hostil ${ }^{12}$. La superación de la autoridad que reprime aquellas tendencias agresivas constituiría una fuente de placer. El profesor M.E. Orellana llama la atención sobre el hecho de que adicionalmente el humor prejuicioso es capaz de acercar identidades sobre la base de prejuicios, que estos serían la contracara de la constitución de identidades: "no hay identidad sin prejuicios"13. El chiste sería, pues, el método humanamente más violento de separar o acercar identidades (y, por lo mismo, anterior y condición constitutiva de la razón): Aglutinamiento libidinoso mediante la risa, satisfacción del impulso destructor mediante el chiste prejuicioso. El castigo omnipresente reduciría la posibilidad de evacuar la agresión y asimismo, la posibilidad de la declaración política en cierto sentido más violenta: el de rehusar a reírse de una broma. Pero también significaría lo no permisible de la risa y la supresión de la satisfacción libidinosa: letargia.

Así podemos agregar una tercera coordenada al campo agonal de la política: el castigo resulta como punto adicional a lo más desigual y lo más igual. Es, en su sentido más abstracto, un fuera de juego de la sociedad entera, un punto en el cual la sociedad estaría fuera de sí: letárgica. El castigo total es, pensando en un triángulo rectángulo, el ángulo opuesto al ángulo recto que representa el punto de la total igualdad: están en el mismo cateto, pues el castigo reconoce a todos los castigados como iguales, iguales en razón de haber sido suspendido de la práctica normal.

Tenemos así, pues, el triángulo que es el campo de juego de la política agonal, demarcados en sus extremos por el eros, la agresión y la letargia. El eros puja hasta la igualdad de todos en una identidad humana abstracta y el impulso agresivo persigue la fragmentación violenta de las identidades a sus partículas indivisibles: los individuos. Finalmente, el castigo es el instrumento que permite recorrer el camino desde lo individual a lo general: permite el reconocimiento del otro como perteneciente a la misma identidad humana al sacarlo del juego en un trecho determinado del tramo, dejarlo letárgico a lo largo del sendero a recorrer. Pero pretender llegar a la meta: la igualdad de todos, conlleva la consecuencia de sacar a la sociedad entera fuera de sí. El desafío consiste entonces en encontrar la balanza entre estas tres fuerzas. Así se logra recobrar la idea de un justo medio aristotélico en un pluralismo equilibrado de identidades.

\section{CRIMEN Y CASTIGO, CULPA Y EXPIACIÓN}

Creo que lo desarrollado anteriormente permite ahora la localización -y así diferenciar la carga semántica- de los dos títulos diferentes "Crimen y Castigo" y "Culpa y Expiación” en lo que llamaré el "triángulo de fuerzas” entre el eros, la agresión y la letargia.

El primero, simple operación lógica que del delito deduce la pena, del crimen el castigo: una deducción que permite calcular el costo y beneficio de incurrir en una falta

\footnotetext{
12 FreUd; Sigmund. Der Witz und seine Beziehung zum Unbewussten. -8a edición- Alemania: Frankfurt am Main, Fischer Taschenbuch Verlag, 2006.

13 Orellana, Miguel E. "Humor y Pluralismo, la victoria más humana", en: Revista de Reflexión Política. Tribuna Americana, Casa de América, Madrid, No 3, abril 2004, p. 136.
} 
contra la ley. Equivale, en términos de Foucault, a una "tecnología de las representaciones", pues actúa directamente sobre ellas al permitir dicho cálculo antes de cometer el acto. Este silogismo claramente se basa sobre un ideal de igualdad abstracto, pues las representaciones utilitaristas permiten una ponderación de intereses en principio con el mismo resultado para toda la humanidad. Diferencias de identidades - de concepciones y sus respectivas ponderaciones- son suspendidas por la letargia general de una sociedad subyugada al cálculo racional de sus intereses a todo momento, que permite la disolución de lo particular como elemento productivo en un aparato social homogenizado, en miras del bien común. Una legislación racional debería evitar el crimen en su totalidad, pues la racionalidad individual permitiría comprender como inútil -relación costo-beneficio negativa- el atentar contra la ley. La obediencia se instala con anterioridad a toda obra agresiva, destructora. Es, en fin, el mismo superego-panóptico de Freud que surge de la idea de la "física social" (recordando a Auguste Comte: sin desmedro del reconocimiento de los ideales éticos detrás de dicha concepción) y que da origen al malestar en la cultura, a un sentido de culpa difuso, a una sociedad letárgica. Un eros, se podría decir, enajenado por un aparato punitivo omnipresente, que exige obediencia adelantada a toda obra.

El problema surge en aquellos casos en que el cálculo racional de los intereses ya no justifican, por ejemplo, la punición de delitos contra la humanidad cometidos por hombres que al momento de ser aplicada la sentencia ya objetivamente no pueden cumplir la pena en razón de su vejez, su senilidad o se deniegan mediante el argumento de que haber obrado bajo órdenes que habrían valido como ley bajo otro régimen. Aquellos dictadores, genocidas, criminales de guerra o vigilantes en los campos de concentración alemanes no pueden ser castigados por ser elementos inútiles en un aparato social productivo -quizás hayan logrado ser grandes empresarios, sigan siendo importantes políticos en la sociedad actual- y en consecuencia deben ser purgados, excluidos del contrato social, sino son hombres y mujeres que debemos reconocer como pertenecientes a nuestra misma identidad, repito: a nuestra identidad, para poder aplicar los criterios de justicia, de convivencia justa, los imperativos vitales de la comunidad que comprendemos como pertenecientes, o aun constitutivos, de nuestra identidad política, y así reafirmar la verdad del crimen cometido. El condenado debe ser culpable en sentido sustancial, culpable en relación a los principios según los cuales ordenamos nuestra convivencia.

Así, los conceptos de "Crimen y Castigo" se disuelven en lo que comprendemos como culpa (sustancial) en relación a los fundamentos morales de nuestra comunidad. No es el lugar aquí para seguir desarrollando una idea del carácter de aquellos "fundamentos morales" que todavía parecen muy difusos y un tanto aleatorios, sujetos a las más diversas interpretaciones, desde una ética discursiva hasta una comprensión iusnaturalista (aunque la primera me parece más prometedora), pero aún así espero que sea posible ahora comprender la relación entre castigo y política en un sentido más profundo de lo que permitiría la concepción mecánica del utilitarismo, que no toma en cuenta el carácter "triangulado" de las identidades políticas: eros, agresión y letargia.

Claro está, que en esta interpretación no es posible relacionar lógicamente lo que sería ahora la culpa y la expiación. Esta última sería, simplemente, el camino de vuelta desde la letargia al campo de juego. Asimismo, el modo de relacionar el crimen y el castigo 
se convierte en la práctica contingente de cada comunidad política, bajo el imperativo de lo que se comprende como culpa. Y así, creo, debemos comprender el crimen de Raskolnikov en "Crimen y Castigo": Primero está la teoría, el asesinato perfecto en persecución de un fin que trasciende los límites morales de la comunidad, la suspensión de lo ético por un fin absoluto (Napoleón y su imperio constituyen el paradigma de aquel pensar). Segundo, el crimen y la lucha por acallar el remordimiento, superar la cobardía vulgar, el enfrentamiento a la vez con la propia fantasía y la investigación policial sin misericordia. Tercero, el castigo, y el campo de trabajo forzado, no queriendo aceptar la culpa, maldiciendo la propia inhabilidad de trascender con el propio ideal mediante un solo asesinato, insignificante por lo demás en relación a los genocidios napoleónicos, de haber fracasado ante la letra de la ley y el aparato punitivo. Letargia en las vastas pampas siberianas, laborando, arrepentido ante la propia incapacidad. Finalmente, el amor de Sonia, aquella mujer piadosa que lo ha estado esperando fielmente. Aquí está la imagen del eros, que atrae a Raskolnikov nuevamente a la comunidad en razón de su misma identidad, de ser objeto del amor. Y al convertirse en sujeto del amor, inicia el proceso de expiación que lo conduce nuevamente al regazo de la sociedad abierta.

\section{REFERENCIAS BIBLIOGRÁFICAS}

ATRIA, Fernando. "Sobre la soberanía y lo político", en Revista Derecho y Humanidades, Santiago, Facultad de Derecho, Universidad de Chile $\mathrm{N}^{\circ} 12,2006$, pp. 47 y ss.

Foucault, Michel. Überwachen und Strafen. Die Geburt des Gefängnisses. $1^{\text {a }}$ edición, Frankfurt am Main, Alemania, Suhrkamp, 1994.

Freud, Sigmund. Das Unbehagen in der Kultur. $10^{\text {a }}$ edición, Frankfurt am Main, Fischer Taschenbuch Verlag, 2007.

Freud, Sigmund. Der Witz und seine Beziehung zum Unbewussten. 8a edición, Frankfurt am Main, Fischer Taschenbuch Verlag, 2006.

Mouffe, Chantal. Über das Politische. Wider die kosmopolitische Illusion. $1^{a}$ edición, Frankfurt am Main, Suhrkamp, 2007.

Orellana, Miguel E. "Humor y Pluralismo, la victoria más humana”, en Revista de Reflexión Politica. Tribuna Americana, Casa de América, Madrid, N³, abril 2004, pp. 128 y ss.

Orellana, Miguel E. Pluralismo: una ética del siglo XX. $2^{\text {a }}$ edición, Santiago, Editorial Universidad de Santiago, 1996.

SchmitT, Carl. Die geistesgeschichtliche Lage des heutigen Parlamentarismus. $6^{a}$ edición, Berlín, Duncker und Humblot, 1985.

Sternberger, Dolf. Drei Wurzeln der Politik. 1ª edición, Frankfurt am Main, Suhrkamp, 1984. 